\title{
Competitividade Tecnológica entre Países: uma análise de dados de patentes na indústria petroquímica
}

\section{Competitiveness Between Countries: an analysis of patents data in the petrochemical industry}

\author{
Eduardo Cardoso Garrido ${ }^{1}$ \\ Renelson Ribeiro Sampaio \\ Fernando Luiz Pellegrini Pessoa ${ }^{2}$ \\ ${ }^{1}$ SEBRAE/BA; SENAI CIMATEC; Universidade Federal da Bahia, Salvador, BA, Brasil \\ ${ }^{2}$ SENAI CIMATEC, Salvador, BA, Brasil
}

\begin{abstract}
Resumo
Os dados resultantes do monitoramento permitem apontar quais países apresentam melhores condições para investimento no cenário mundial tecnológico e, assim, subsidiar ações destinadas ao desenvolvimento de negócios. O objetivo do presente trabalho foi o de verificar se o investimento tecnológico por meio de patentes da indústria petroquímica está ligado à competitividade de um país. Utilizou-se o Questel Orbit para busca e análise de dados contidos em publicações de patentes. Diferentes indicadores foram utilizados para efetuar a análise: PIB PPC; quantitativo de patentes com reivindicação de prioridade em um país; e o ICG. Verificou-se uma forte ligação entre o número de depósitos de patentes com o PIB PPC e o nível de investimento em P\&D. Entretanto, ainda que determinado país se destaque quanto aos indicadores citados, esta correlação não é aplicável à totalidade dos países. Evidencia-se forte presença da China, dos EUA e do Japão no âmbito da publicação de patentes.
\end{abstract}

Palavras-chave: Patentes. Prospecção Tecnológica. Indústria Petroquímica.

\begin{abstract}
The data resulting from monitoring allow to indicate which countries present best conditions for investment in the technological world scenario and, thus, subsidize actions aimed at the development of business. The objective of this work was to verify if the technological investment by patents of the petrochemical industry is linked to the competitiveness of a country. Questel Orbit was used to search and analyze data contained in patent publications. Different indicators were used to carry out the analysis: GDP PPC; number of patents with priority claims in a country; and the GCI. There was a strong link between the number of patent deposits with GDP PPC and the level of investment in $\mathrm{R} \& \mathrm{D}$. However, although a country is highlighted in relation to the mentioned indicators, this correlation is not applicable to all countries. There is a strong presence of China, USA and Japan in the context of patent publication.
\end{abstract}

Keywords: Patents. Technological Prospecting. Petrochemical Industry.

Área tecnológica: Prospecções Tecnológicas de Assuntos Específicos. 


\section{Introdução}

A Indústria Petroquímica encontra-se em um período de contínua transição, de constante reinvenção. A antiga caracterização da localização, como fator chave, permanece preponderante, porém outros aspectos têm se tornado cada vez mais relevantes para o destaque de indústrias (CETINKAYA e outros, 2017) .

Neste cenário, a corrida contínua por vantagens que agreguem Competitividade aos negócios torna-se um diferencial para a sobrevivência das empresas na busca por incrementos, melhorias em seus produtos, processos, serviços para que se destaquem perante os seus concorrentes. Estes benefícios podem resultar em ganhos ora sob o ponto de vista da redução de custos, ora sob a perspectiva do aumento de faturamento.

A Informação é a moeda de troca, e as indústrias vivem uma era de Conhecimento: conhecimento sobre o mercado, sobre as relações de troca, sobre a tecnologia, sobre o cliente, sobre o negócio, sobre os processos.

Dispor de informações confiáveis permite que o tomador de decisão experimente riscos calculados perante as situações e que, desse modo, antecipe a geração de oportunidades.

Como exemplos de desafios podem ser realizados alguns questionamentos com base em situações vividas pelas empresas. Por exemplo, qual a contribuição da competitividade tecnológica em um cenário em que questões como matéria-prima, logística, capacitação tecnológica e mercado estão adequadamente formatadas? Quais são os principais players mundiais?

As patentes, como ferramentas de estratégia competitiva, são uma fonte de pesquisa extremamente completa: $70 \%$ das informações tecnológicas aí contidas não estão disponíveis em qualquer outro tipo de fonte de informação. De acordo com a Organização Mundial da Propriedade Intelectual (OMPI), o número de pedidos de patente é de aproximadamente 2,5 milhões a cada ano, com a concessão de cerca de 1,2 milhões de patentes. As patentes subsidiam o "desenvolvimento de novas tecnologias, monitoramento de concorrentes, identificação de tendências tecnológicas, investimentos" (INPI, 2016) .

Uma patente é um direito exclusivo concedido pelo Estado relativamente a uma invenção (ou modelo de utilidade), que atende ao requisito de novidade, envolve uma atividade inventiva (ou ato inventivo) e é suscetível de aplicação industrial (INPI, 2013).

Os países que se destacam quanto ao número de prioridades de publicação de patentes reivindicadas no cenário de Indústrias de petróleo, gás ou coque, Gases técnicos contendo monóxido de carbono, Combustíveis, Lubrificantes, Turfa são aqueles que se destacam sob o aspecto de competitividade global?

Neste documento são apresentados os resultados de uma pesquisa patentária desenvolvida por meio da ferramenta de busca do Questel Orbit para dados mundiais de patentes no cenário de Indústrias de petróleo, gás ou coque, Gases técnicos contendo monóxido de carbono, Combustíveis, Lubrificantes, Turfa para o período situado entre os anos de 1980 e 2017.

O objetivo do presente trabalho é o de, a partir da análise de séries de dados históricas, verificar se o investimento tecnológico por meio de patentes está necessariamente ligado à competitividade de um determinado país e ao progresso técnico e à geração de receita de suas indústrias petroquímicas. 


\subsection{O Desafio da Competitividade e a Indústria Petroquímica}

No âmbito da indústria petroquímica, os investimentos são promovidos de modo a garantir e a ampliar os diferenciais de competitividade.

Segundo a Indian Oil (2016), estes esforços devem ser direcionados com foco em 3 (três) fatores principais: energia e matérias-primas; crescimento da demanda; e tecnologia.

Ao tratar do fator de disponibilidade de energia e matérias-primas, verifica-se um aspecto da composição de preços de venda de produtos ou da prestação de serviços, já que a proximidade e fácil disponibilidade de insumos pode impactar em média $60 \%$ a $70 \%$ dos custos de produtos químicos, ou seja, daí decorre grande importância na competitividade industrial.

Esta mesma proximidade é relevante quando se fala de disponibilidade de mercados: os clientes não devem estar apenas próximos, eles devem demandar contínua e permanentemente. Este encurtamento de distâncias não deve ocorrer apenas de forma física sob o ponto de vista da infraestrutura, da logística e da cadeia de suprimentos. A proximidade também deve existir por meio de estímulos, das mídias sociais, e diante de um mercado global e imediatista, especialmente do Marketing Digital.

Assim, a tecnologia deve estar presente, sempre que possível, nas diversas etapas de uma empresa, desde o momento da captação e transformação de insumos até a entrega final ao Cliente, com fidelização e encantamento permanentes. Ao unificar estes 3 (três) principais fatores, a indústria petroquímica consegue otimizar processos, reduzir custos e promover mercados em seu favor.

Em complemento à ótica apresentada pela Indian Oil, o Fórum Econômico Mundial, por meio do Relatório de Competitividade Global, apresenta 3 (três) grandes grupos associados à Competividade (WEF, 2014):

a) Requerimentos básicos (Estágio 1): apresentam-se mais importantes para economias em um estágio mais inicial, que sejam impulsionadas por acumulação de fatores estruturais, como saúde, educação, ou seja, economias com um menor estágio de desenvolvimento. Divide-se em 4 (quatro) pilares, quais sejam: Instituições; Infraestrutura; Ambiente Macroeconômico; Saúde e Educação Primária;

b) Estimuladores de eficiência (Estágio 2): são destinadas a economias em um estágio intermediário, contemplando 6 (seis) pilares: educação superior e treinamento; eficiência no mercado de bens; eficiência no mercado de trabalho; desenvolvimento de mercado financeiro; capacidade de absorção tecnológica; e tamanho do mercado;

c) Inovação e sofisticação dos negócios (Estágio 3): São mais relevantes para economias impulsionadas por inovação, mais desenvolvidas, por já apresentarem alicerces bem estruturados quando aos outros 10 (dez) pilares anteriormente referidos nos Estágios 1 e 2 .

Estes 3 (três) grandes grupos englobam 12 (doze) itens essenciais para a composição do Índice de Competitividade Global, conforme a Figura 1. 
Figura 1 - Índice de Competitividade Global (ICG)

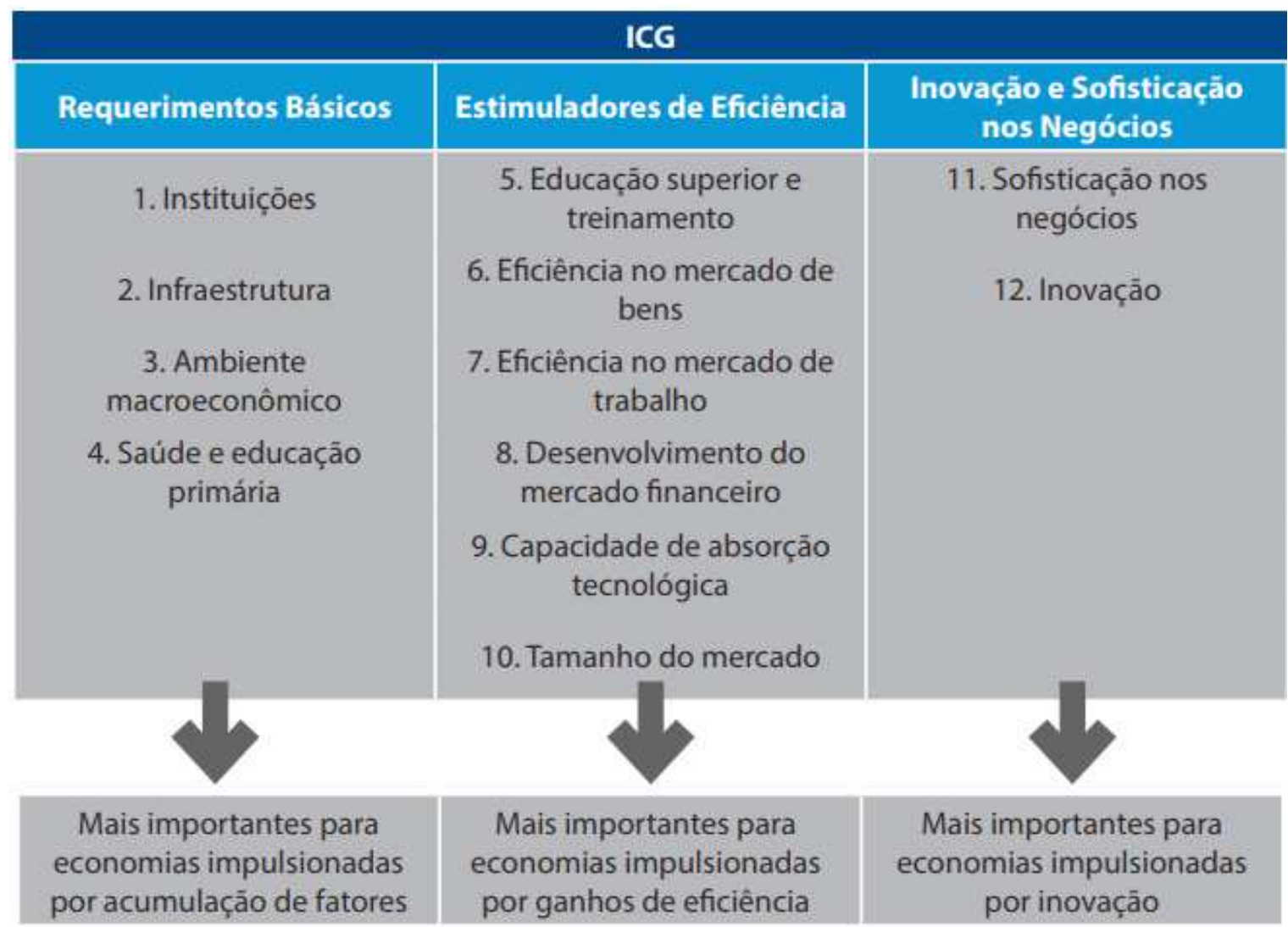

Fonte: Adaptado de WEF (2014 apud PINHEIRO; FIGUEIREDO, 2015)

Por este estudo o Brasil está inserido entre as 24 (vinte e quatro) economias que se localizam em transição entre os estágios 2 e 3. Com base neste Índice de Competitividade Global (ICG), o Brasil evoluiu da 66 a posição (em 125 países) para a 57ª (em 144 países) entre 2006 e 2014, sendo que grande parte do avanço ocorreu de 2006 a 2010. "O Brasil melhorou sua posição no ranking do indicador apenas nos pilares ambiente macroeconômico, educação superior e treinamento e desenvolvimento do mercado financeiro". No critério inovação, pelo contrário, o Brasil caiu da $37^{a}$ posição para a $62^{\mathrm{a}}$ posição neste mesmo período (PINHEIRO; FIGUEIREDO, 2015) .

Em complemento a tais resultados, e de modo a ratificar o baixo desenvolvimento do Brasil entre o período de 2010 e 2015, segundo o estudo sobre competitividade mundial desenvolvido a partir de uma amostra de 61 (sessenta e um) países pelo Institute for Management Development World Competitiveness Center, o Brasil caiu da $38^{\circ}$ posição para $56^{\circ}$ posição entre os anos de 2010 e 2015 (CNI, 2018).

A Figura 2 apresenta o Gráfico contemplando a composição do Índice de Competitividade Global (ICG) para o Brasil, em comparação à América Latina e Caribe, para a Edição 20172018, edição em que passou a ocupar a 80ª posição entre os 137 países avaliados, configurando uma queda bastante expressiva. No aspecto inovação, o Brasil ocupa a $85^{a}$ posição. 
Figura 2 - Gráfico contemplando a composição do Índice de Competitividade Global (ICG) para o Brasil, em comparação à América Latina e Caribe, para a Edição 2017-2018

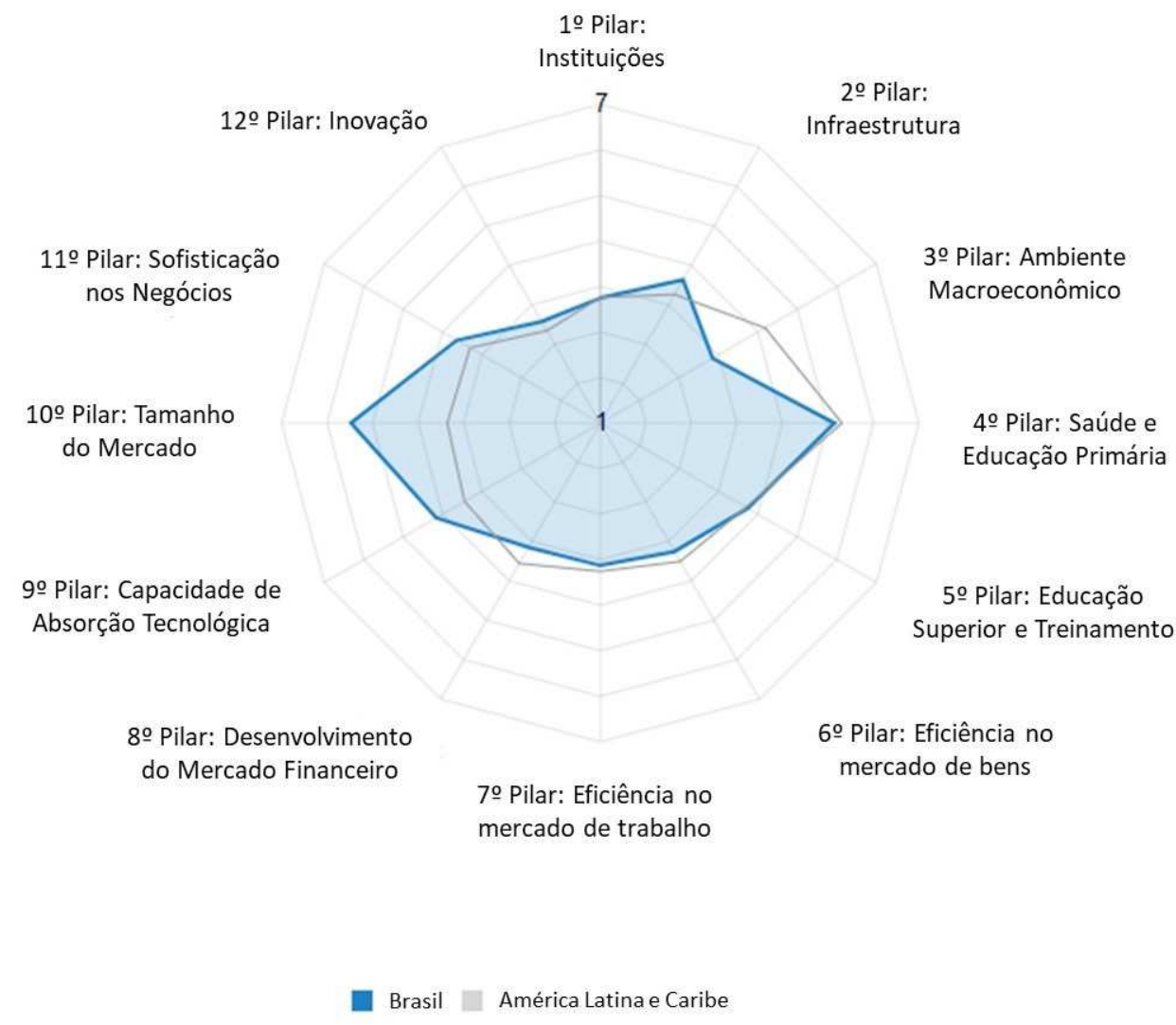

Fonte: Adaptado pelos autores deste artigo (2018) de WEF (2018)

No âmbito dos Requerimentos Básicos (pilares 1, 2, 3 e 4), o Brasil ocupa a $104^{a}$ posição, com nota 4,1 (sendo 1,0 a nota mínima e 7,0 a nota máxima possível). No âmbito dos Estimuladores de Eficiência (pilares 5, 6, 7, 8, 9 e 10) o Brasil ocupa a 60ª posição, com nota 4,3. Na Inovação e Sofisticação dos Negócios o Brasil ocupa a 65ª posição, com nota 3,7.

Entre os principais problemas para a geração de negócios e oportunidades apontados pelo estudo, tem-se: taxas de impostos (18,6\%); regulamentação trabalhista restritiva (12,5\%); corrupção (12.3\%); burocracia governamental ineficiente $(12,0 \%)$; fornecimento inadequado de infraestrutura $(10,4 \%)$; instabilidade política $(7,4 \%)$; regulamentos fiscais $(5,4 \%)$; acesso ao financiamento $(5,2 \%)$; instabilidade do governo/golpes $(4,2 \%)$; força de trabalho inadequadamente educada (4,0\%); inflação $(2,1 \%)$; crime e roubo $(1,9 \%)$; capacidade insuficiente para inovar $(1,8 \%)$; má ética de trabalho na força de trabalho nacional $(1,1 \%)$; saúde pública deficiente $(1,1 \%)$; regulamentos para moeda estrangeira $(0,1 \%)$.

Enquanto o Brasil apresenta-se na $80^{\mathrm{a}}$ posição quanto ao Índice de Competitividade Global (ICG), a Suíça apresenta-se na $1^{a}$ posição; os Estados Unidos encontram-se na $2^{\mathrm{a}}$ posição; a Alemanha na $5^{a}$ posição; o Japão, na $9^{a}$ posição; a Coreia na $26^{a}$ posição; a China na $27^{a}$ posição; e a Índia na $40^{\mathrm{a}}$ posição.

Diante do fato de o eteno apresentar-se como um dos insumos mais importantes sob o aspecto da competitividade da indústria petroquímica, quando comparado relativamente ao mercado global, o que se observa é que os principais players globais apresentam unidades de 
produção com escala maior que o Brasil. A Figura 3 apresenta a capacidade instalada mundial de produção de eteno, entre os anos de 2000 e 2012.

Figura 3 - Capacidade instalada mundial de produção de eteno: 2000 a 2012 (Milhares de toneladas por ano)

\begin{tabular}{|c|c|c|c|c|c|c|c|c|c|c|c|c|c|}
\hline Regiobes & 2000 & 2001 & 2002 & 2003 & 2004 & 2005 & 2006 & 2007 & 2003 & 2009 & 2010 & 2011 & 2012 \\
\hline América do Norte & 31.464 & 32.100 & 33.175 & 33.010 & 32.920 & 33.585 & 33.630 & 33.630 & 33.915 & 31.543 & 31.145 & 31.625 & 31.815 \\
\hline EUA & 27.104 & 26.925 & 27.965 & 27.765 & 27.679 & 28.320 & 28.250 & 28.250 & 28.725 & 26.448 & 26.050 & 26.530 & 26.720 \\
\hline Canadá & 4.360 & 4.360 & 5.175 & 5.210 & 5.245 & 5.265 & 5.390 & 5.380 & 5.190 & 5.095 & 5.095 & 3.095 & 5.095 \\
\hline Ásia/Pacífico & 26.263 & 27.832 & 29.678 & 30.753 & 32.641 & 34.505 & 36.957 & 39.415 & 40.510 & 41.701 & 48.959 & 50.864 & 51.862 \\
\hline มอpลี่ & 7.410 & 7.043 & 7.193 & 7.248 & 7.839 & 7.839 & 8.013 & 8.007 & 7.962 & 8.023 & 8.023 & 7.822 & 7.624 \\
\hline Gins & 4.625 & 4.890 & 5.360 & 6.585 & 6.620 & 7.980 & 9.795 & 10.780 & 10.840 & 11.785 & 15.848 & 16.884 & 17.765 \\
\hline Coréia do Sul & 9.250 & 5.340 & 5.640 & 9.720 & 6.030 & 6.055 & 6.245 & 6.780 & 7.249 & 7,345 & 7.495 & 7.890 & 8.185 \\
\hline Taiwan & 1.665 & 2.415 & 2.515 & 2.800 & 2.802 & 2.815 & 2.865 & 3.515 & 4.119 & 4.115 & 4.115 & 4.115 & 4.035 \\
\hline India & 2.287 & 2.478 & 2.463 & 2.493 & 2.983 & 2.703 & 2.876 & 2.930 & 2.895 & 2895 & 3.725 & 3.939 & 3.935 \\
\hline Triländis & 1.826 & 1.901 & 2.062 & 2.062 & 2.012 & 2.300 & 2.306 & 2.426 & 2.436 & 2.526 & 4.151 & 4.436 & 4.436 \\
\hline Outros & 3.200 & 3.765 & 4.459 & 4.745 & 4.795 & 4.813 & 4.857 & 4.977 & 5.017 & 5.012 & 3.602 & 9.782 & 5.882 \\
\hline Europs Ocidental & 23.880 & 24.380 & 25.610 & 26.110 & 26.385 & 26.990 & 27.540 & 27.695 & 27.955 & 27.100 & 27.138 & 27.020 & 26.680 \\
\hline Alemsnha & 5.215 & 5.325 & 5.435 & 9.940 & 5.559 & 5.610 & 5.690 & 9.720 & 5.870 & 5.700 & 5.885 & 9.745 & 5.625 \\
\hline Holands & 3.079 & 3.225 & 3.900 & 3.850 & 3.850 & 3.850 & 3.850 & 3.850 & 3.850 & 3.855 & 3.850 & 3.860 & 3.860 \\
\hline Franço & 3.265 & 3.285 & 3.370 & 3.410 & 3.450 & 3.440 & 3.410 & 3.410 & 3.410 & 3.190 & 3.190 & 3.190 & 3.190 \\
\hline Reino Unido & 2.590 & 2.600 & 2.850 & 2.870 & 2.870 & 2.870 & 2.870 & 2.870 & 2.870 & 2870 & 2.820 & 2.709 & 2.705 \\
\hline Itáía & 2.165 & 2.175 & 2.185 & 2.185 & 2.185 & 2.185 & 2.185 & 2.185 & 1.975 & 1.930 & 1.975 & 1.885 & 1.725 \\
\hline Bélegica & 1.915 & 1.970 & 2.040 & 2.115 & 2.230 & 2.255 & 2255 & 2.285 & 2.520 & 2.325 & 2.535 & 2.539 & 2.535 \\
\hline Espaning & 1.405 & 1.430 & 1.430 & 1.490 & 1.530 & 1.530 & 1.630 & 1.630 & 1.630 & 1.630 & 1.403 & 1.630 & 1.630 \\
\hline Outros & 4.250 & 4.370 & 4.500 & 4.660 & 4.719 & 5.250 & 5.660 & 9.745 & 3.830 & 5.600 & 3.470 & 9.470 & 5.410 \\
\hline Oriente Médio & 6.267 & 8.332 & 8.992 & 9.412 & 9.932 & 11.007 & 11.782 & 12.992 & 15.512 & 18.812 & 23.842 & 26.302 & 27.302 \\
\hline Arábia Saudita & 3.885 & 5.910 & 5960 & 6.060 & 6.420 & 7.170 & 7.490 & 7.710 & 7.905 & 9.959 & 12920 & 14.210 & 14.710 \\
\hline Irõ & 707 & 707 & 707 & 732 & 767 & 1.092 & 1.487 & 2.332 & 4.487 & 4.922 & 5.332 & 5.457 & 5.957 \\
\hline Kuwgit & 800 & 800 & 850 & 900 & 900 & 950 & 1000 & 1.035 & 1.850 & 1850 & 1.850 & 1.850 & 1.850 \\
\hline Catar & 525 & 525 & 525 & 900 & 1.025 & 1.025 & 1.025 & 1.110 & 1.245 & 1.245 & 2.225 & 2.545 & 2.545 \\
\hline Outros & 390 & 390 & 950 & 820 & 820 & 820 & 830 & 840 & 840 & 840 & 1.515 & 2.240 & 2.240 \\
\hline B́frica & 1.450 & 1.600 & 1.600 & 1.690 & 1.720 & 1.730 & 1.730 & 1.730 & 1.880 & 1.930 & 1.930 & 1.630 & 1.750 \\
\hline Europs Oriental & 4.120 & 4.160 & 4.275 & 4.390 & 3.960 & 3.995 & 4.105 & 4.275 & 4.155 & 4.025 & 4.095 & 4.275 & 4.315 \\
\hline Rúrsis & 2.920 & 2.920 & 2.935 & 3.090 & 3.120 & 3.155 & 3.265 & 3.435 & 3.435 & 3.435 & 3.435 & 3.435 & 3.435 \\
\hline Outros & 1.200 & 1.240 & 1.340 & 1.340 & 840 & 840 & 840 & 840 & 720 & 590 & 660 & 840 & 840 \\
\hline América Latins & 5.278 & 5.618 & 5.703 & 5.451 & 5.668 & 6.333 & 6.458 & 6.538 & 6.875 & 6.875 & 7.035 & 6.975 & 6.975 \\
\hline Brasil (") & 2.835 & 2.835 & 2.835 & 2.835 & 2.919 & 3.435 & 3.435 & 3.435 & 3.772 & 3.772 & 3.952 & 3.952 & 3.952 \\
\hline México & 1.360 & 1.360 & 1.360 & 1.360 & 1.380 & 1.380 & 1.490 & 1.560 & 1.560 & 1560 & 1.540 & 1.480 & 1.480 \\
\hline Argentins & 323 & 663 & 748 & 745 & 733 & 798 & 783 & 783 & 783 & 783 & 783 & 783 & 783 \\
\hline Venezuels & 600 & 600 & 600 & 350 & 480 & 600 & 600 & 600 & 600 & 600 & 600 & 600 & 600 \\
\hline Outros & 160 & 160 & 160 & 160 & 160 & 160 & 160 & 160 & 160 & 160 & 160 & 160 & 160 \\
\hline Total Mundo & 98.722 & 104.022 & 109.022 & 110.806 & 113.226 & 118.145 & 122.202 & 126.275 & 130.802 & 131.986 & 144.144 & 148.691 & 150.699 \\
\hline
\end{tabular}

Fonte: LAFIS (2016 apud VIANA, 2016)

Por meio da Figura 3, verifica-se que Estados Unidos, China, Arábia Saudita, Coreia do Sul, Japão, Irã, Alemanha e Canadá são exemplos de economias que superam o Brasil.

Ao se abordar o quantitativo de patentes como ferramenta de análise de competitividade tecnológica, faz-se de extrema relevância examinar o conteúdo do Tratado de Cooperações em Matéria de Patentes (PCT, Patent Cooperation Treaty) (WIPO, 1970). Ainda que faça parte do Tratado, contudo, baixos investimentos em P\&D colocam o Brasil em desvantagem perante os seus competidores internacionais:

Em termos de investimento, de acordo com dados do Ministério da Ciência, Tecnologia, Inovações e Comunicações (MCT) de 2009, o Brasil investiu 1,42\% do seu PIB em 
ciência e tecnologia, o que é considerado uma taxa baixa quando comparado a outros países de industrialização tardia. Os indicadores contidos no relatório da Organização Mundial da Propriedade Intelectual (OMPI) de 2009 mostram que no Brasil (dados referentes a 2006) $84,2 \%$ dos pedidos de patentes depositados no Instituto Nacional da Propriedade Industrial (INPI) foram de não-residentes e que 90,2\% das patentes concedidas também eram de não-residentes. Em 2008 o número total de pedidos de proteção no exterior para patentes brasileiras via The Patent Cooperation Treaty (PCT) foi de apenas 444 (CNI, 2018).

\section{Metodologia}

A abordagem metodológica e as etapas de investigação são promovidas conforme a seguinte estratégia de busca:

a) Definição da temática a ser abordada: indústrias de petróleo e gás;

b) Pesquisa inicial por meio do levantamento bibliográfico de publicações, artigos, capítulos de livros por intermédio: da ferramenta de Pesquisa Qualis Periódicos, da Plataforma Sucupira, do Portal de Periódico CAPES; da SciELO; do Google Scholar; da Science Direct; de sites Institucionais e de Eventos;

c) Identificação da classificação da International Patent Classification (IPC) correlata ao tema com base nos resultados de pesquisa e dos termos técnicos encontrados. A IPC é um sistema de classificação internacional estruturado em classes, subclasses, grupos principais e grupos, criada a partir do Acordo de Estrasburgo, totalizando 70.000 (setenta mil) grupos (INPI, 2017);

d) A codificação estabelecida como escopo de pesquisa é a IPC C10, que corresponde a Petroleum, gas or coke industries; technical gases containing carbon monoxide; fuels; lubricants; peat (indústrias de petróleo, gás ou coque; gases técnicos contendo monóxido de carbono; combustíveis; lubrificantes; turfa);

e) Definição do período para análise e do cenário: período de 1899 a 2018, cenário mundial de patentes;

f) Definição da plataforma a ser utilizada para a busca. Para a finalidade do presente trabalho utilizou-se a plataforma denominada Questel Orbit, um sistema de busca e análise de informações contidas em publicações de patentes em mais de 90 (noventa) países. Dispõe de recursos avançados de visualização, exportação e análises de grandes conjuntos de informações que contribuem para uma construção de plataformas tecnológicas, bem como fusões e aquisições de empresas (AXONAL, 2017);

g) Estruturação de scripts para geração de dados a partir de informações do Inventário WIPO;

h) Acesso à base de dados de patentes por meio do sistema de busca avançada da ferramenta Questel Orbit;

i) Tratamento e análise dos resultados obtidos: os dados são organizados por país com reivindicações de prioridade, tendo sido elencados os 30 (trinta) principais países. Os resultados são comparados com Indicadores como o PIB PPC (Produto Interno Bruto - Paridade do Poder de Compra) e o consumo de polímeros pelos países, dentre outros Indicadores;

j) Apresentação de considerações finais e proposição de oportunidades para futuros trabalhos. 


\section{Resultados e Discussão}

A análise do quantitativo de publicações de famílias de patentes no âmbito da Indústria Petroquímica é promovida com base em scripts construídos a partir de informações do Inventário WIPO: a codificação IPC C10 corresponde a Petroleum, gas or coke industries; technical gases containing carbon monoxide; fuels; lubricants; peat (indústrias de petróleo, gás ou coque; gases técnicos contendo monóxido de carbono; combustíveis; lubrificantes; turfa).

O primeiro país de prioridade é aquele onde a patente é registrada pela primeira vez antes de ser (possivelmente) estendida a outros países (OECD, 2006). De maneira geral os depositantes que desejam proteger sua invenção em mais de um país costumam reivindicar a prioridade de sua patente primeiramente em seu próprio país ou região para, após, procederem o pedido em outros países (WIPO, 2017).

O Quadro 1 relaciona os 30 (trinta) principais países em que foram reivindicadas prioridades de publicações de patente, independentemente de ser ou não o primeiro país.

Quadro 1 - Relação de 30 (trinta) principais países em que foram reivindicadas prioridades de publicações de patente entre o período de 1899 e abril de 2018, independentemente de ser ou não o primeiro país

\begin{tabular}{|c|c|c|c|c|}
\hline $\begin{array}{l}\text { Posição } \\
\text { Patentes }\end{array}$ & $\begin{array}{c}\text { País em que houve a } \\
\text { ReivindicaÇão de Prioridade }\end{array}$ & $\begin{array}{l}\text { Quantidade de Famílias } \\
\text { De Patentes Publicadas }\end{array}$ & $\begin{array}{l}\text { Posição ICG } \\
2017 \text { InOvaÇão }\end{array}$ & $\begin{array}{l}\text { Posição ICG } \\
2017 \text { Geral }\end{array}$ \\
\hline 1 & China $(\mathrm{CN})$ & 82.896 & 28 & 27 \\
\hline 2 & Estados Unidos (US) & 80.446 & 2 & 2 \\
\hline 3 & Japão (JP) & 59.119 & 8 & 9 \\
\hline 4 & Alemanha (DE) & 33.743 & 5 & 5 \\
\hline 5 & WIPO (WO) & 26.589 & $\mathrm{~N} / \mathrm{A}$ & $\mathrm{N} / \mathrm{A}$ \\
\hline 6 & França (FR) & 20.129 & 17 & 22 \\
\hline 7 & Reino Unido (GB) & 16.701 & 12 & 8 \\
\hline 8 & União Soviética (SU) & 10.121 & $\mathrm{~N} / \mathrm{A}$ & $\mathrm{N} / \mathrm{A}$ \\
\hline 9 & Coreia (KR) & 8.570 & 18 & 26 \\
\hline 10 & European Patent Office (EPO) & 6.992 & $\mathrm{~N} / \mathrm{A}$ & $\mathrm{N} / \mathrm{A}$ \\
\hline 11 & Federação Russa (RU) & 6.635 & 49 & 38 \\
\hline 12 & Holanda (NL) & 5.024 & 6 & 4 \\
\hline 13 & Bélgica (BE) & 4.736 & 16 & 20 \\
\hline 14 & Polônia (PL) & 3.245 & 59 & 39 \\
\hline 15 & Canadá (CA) & 2.773 & 23 & 14 \\
\hline 16 & $\begin{array}{l}\text { Alemanha, excluindo o território } \\
\text { que, antes de } 3 \text { de Outubro de } \\
\text { 1990, constituía a República } \\
\text { Federal da Alemanha (DD) }\end{array}$ & 2.154 & $\mathrm{~N} / \mathrm{A}$ & $\mathrm{N} / \mathrm{A}$ \\
\hline 17 & Itália (IT) & 2.034 & 34 & 43 \\
\hline 18 & Suíça $(\mathrm{CH})$ & 1.926 & 1 & 1 \\
\hline
\end{tabular}




\begin{tabular}{|c|c|c|c|c|}
\hline $\begin{array}{l}\text { Posição } \\
\text { Patentes }\end{array}$ & $\begin{array}{c}\text { País em QUe houve a } \\
\text { Reivindicação de Prioridade }\end{array}$ & $\begin{array}{l}\text { Quantidade de Famílias } \\
\text { De Patentes Publicadas }\end{array}$ & $\begin{array}{l}\text { Posição ICG } \\
2017 \text { InovaÇão }\end{array}$ & $\begin{array}{l}\text { Posição ICG } \\
2017 \text { GeraL }\end{array}$ \\
\hline 19 & Tailândia $(\mathrm{TH})$ & 1.876 & 50 & 32 \\
\hline 20 & Índia (IN) & 1.875 & 29 & 40 \\
\hline 21 & Austrália (AU) & 1.859 & 27 & 21 \\
\hline 22 & Brasil (BR) & 1.812 & 85 & 80 \\
\hline 23 & Ucrânia (UA) & 1.748 & 61 & 81 \\
\hline 24 & Finlândia (FI) & 1.672 & 4 & 10 \\
\hline 25 & Tchecoslováquia, até 1993 (CS) & 1.277 & $\mathrm{~N} / \mathrm{A}$ & $\mathrm{N} / \mathrm{A}$ \\
\hline 26 & Suécia (SE) & 1.094 & 7 & 7 \\
\hline 27 & Espanha (ES) & 1.011 & 42 & 34 \\
\hline 28 & Romênia (RO) & 999 & 96 & 68 \\
\hline 29 & Áustria (AT) & 950 & 13 & 18 \\
\hline 30 & África do Sul (ZA) & 911 & 39 & 61 \\
\hline
\end{tabular}

Fonte: Elaborada pelos autores deste artigo (2018) com dados gerados pelo Questel Orbit e adaptados de WEF (2018)

No Quadro 1, países como China, Estados Unidos, Japão e Alemanha destacam-se entre os principais, com o Brasil na $22^{\mathrm{a}}$ posição.

"A taxa de inovação de um país pode ser aferida pelo valor total do investimento (público e privado) em pesquisa e desenvolvimento (P\&D) em relação ao seu PIB" (CNI, 2018) . O Quadro 2 apresenta o Produto Interno Bruto (PIB) Paridade Poder de Compra (PPC), em bilhões de US\$, para os 15 (quinze) principais países no ano de 2016.

Quadro 2 - Produto Interno Bruto (PIB) Paridade Poder de Compra (PPC), em bilhões de US\$ - 2016

\begin{tabular}{|c|c|c|}
\hline Posıção & País & US\$ BILHÕES \\
\hline $1^{\circ}$ & China & $21.291,77$ \\
\hline $2^{\circ}$ & Estados Unidos & $18.569,10$ \\
\hline $3^{\circ}$ & Índia & $8.662,35$ \\
\hline $4^{\circ}$ & Japão & $5.237,79$ \\
\hline $5^{\circ}$ & Alemanha ${ }^{\circ}$ & $3.980,28$ \\
\hline $6^{\circ}$ & Rússia & $3.799,70$ \\
\hline $7^{\circ}$ & Brasil & $3.141,34$ \\
\hline $8^{\circ}$ & Indonésia & $3.032,09$ \\
\hline $9^{\circ}$ & Reino Unido & $2.785,56$ \\
\hline $10^{\circ}$ & França & $2.733,68$ \\
\hline $11^{\circ}$ & México & $2.315,65$ \\
\hline $12^{\circ}$ & Itália & $2.234,50$ \\
\hline $13^{\circ}$ & Turquia & $1.988,33$ \\
\hline
\end{tabular}




\begin{tabular}{|c|c|c|}
\hline Posição & País & US\$ BILHÕES \\
\hline $14^{\circ}$ & Coreia do Sul & $1.934,03$ \\
\hline $15^{\circ}$ & Arábia Saudita & $1.750,86$ \\
\hline
\end{tabular}

Nota 1: Estimativa do Fundo Monetário Internacional (FMI).

Fonte: FMI (2017 apud FUNAG, 2017)

Ao analisar o PIB PPC (Produto Interno Bruto - Paridade do Poder de Compra) dos 15 (quinze) principais países no ano de 2016, constantes no Quadro 1, verifica-se a presença de países constantes no Quadro 2, respectivamente: China, Estados Unidos, Índia, Japão, Alemanha, Rússia, Brasil, Reino Unido, França, Itália e Coreia.

Conforme o Índice de Competitividade Global (ICG) estabelecido pelo Fórum Econômico Mundial, para a Edição 2017-2018, entre os 137 (cento e trinta e sete) países avaliados, os Estados Unidos encontram-se na $2^{\mathrm{a}}$ posição; a Alemanha na $5^{\mathrm{a}}$ posição; o Reino Unido na $8^{\mathrm{a}}$ posição; o Japão, na $9^{a}$ posição; a França na $22^{a}$ posição; a Coreia na $26^{a}$ posição; a China na $27^{a}$ posição; a Rússia na $38^{a}$, a Índia na $40^{a}$ posição e a Itália na $43^{a}$ posição.

Estudiosos consideram que existe uma forte ligação entre o número de depósitos de patentes com o PIB e o nível de investimento em P\&D. A China, o Japão e os Estados Unidos compõem o topo deste ranking. Em 2007, cerca de mais de 59\% de todos os depósitos de patente provieram apenas destes três países. $\mathrm{O}$ aumento substancial do número de pedidos de patentes da China e República da Coreia nos últimos anos tem reduzido o gap entre os dois primeiros colocados (Estados Unidos e Japão). Em 2007, a China e a República da Coreia depositaram mais pedidos de patentes em relação ao PIB ou investimentos em P\&D do que os Estados Unidos (CNI, 2018) .

Tais países também constam relacionados no Quadro 3, adiante enunciado.

Quadro 3 - Principais Países Consumidores de Polímeros no Mundo, em Milhões de Toneladas Métricas (MMT)

\begin{tabular}{|c|c|c|}
\hline Posıção & País & Consumo EM MMT NO ANO DE 2015 \\
\hline $\mathbf{1}$ & Estados Unidos & 38,9 \\
\hline $\mathbf{2}$ & China & 31,3 \\
\hline $\mathbf{3}$ & Índia & 12,5 \\
\hline $\mathbf{4}$ & Japão & 11,5 \\
\hline $\mathbf{5}$ & Alemanha & 9,4 \\
\hline $\mathbf{6}$ & Coreia do Sul & 7,4 \\
\hline $\mathbf{7}$ & Itália & 6,8 \\
\hline $\mathbf{8}$ & Brasil & 6,7 \\
\hline $\mathbf{9}$ & Comunidade dos Estados Independentes & 6,2 \\
\hline $\mathbf{1 0}$ & França & 6,1 \\
\hline
\end{tabular}

Fonte: Chemicals and Petrochemicals Manufacturers Association (CPMA) (2016 apud Indian Oil, 2016) 
O Quadro 3 indica quais os principais países consumidores de polímeros no mundo: Estados Unidos, China, Índia, Japão, Alemanha, Coreia do Sul, Itália, Brasil, Comunidade dos Estados Independentes (CEI) e França. Segundo o DEPEC-BRADESCO (2017), os preços internacionais sofrem a influência de demanda dos seguintes países: EUA, União Europeia e China.

Por último, é possível perceber uma outra relação entre os países ora relacionados no mérito de reivindicação de prioridades de publicações de patentes: nesta relação constam os maiores importadores e exportadores mundiais de produtos químicos.

Admitindo-se, contudo, apenas a $1^{a}$ (primeira) reivindicação de prioridade, ou seja, aquele país definido como o primeiro em que se reivindicará a prioridade, há uma pequena mudança na configuração dos países relacionados no Quadro 1 em relação ao Quadro 4, adiante enunciado, porém com impacto significativo para o Brasil.

Quadro 4 - Relação de 30 (trinta) principais países em que foram reivindicadas prioridades de publicações de patente entre o período de 1899 e maio de 2018

\begin{tabular}{|c|c|c|c|c|}
\hline $\begin{array}{l}\text { Posição } \\
\text { Patentes }\end{array}$ & $\begin{array}{l}\text { País em Que houve a } \mathbf{1}^{\text {a }} \text { ReivindicaÇão } \\
\text { De PrioRidade }\end{array}$ & $\begin{array}{l}\text { Quantidade de Famílias } \\
\text { De Patentes Publicadas }\end{array}$ & $\begin{array}{c}\text { Posıção } \\
\text { ICG } 2017 \\
\text { INOVAÇÃo }\end{array}$ & $\begin{array}{c}\text { Posição } \\
\text { ICG } 2017 \\
\text { GERAL }\end{array}$ \\
\hline 1 & China $(\mathrm{CN})$ & 83.361 & 28 & 27 \\
\hline 2 & Estados Unidos (US) & 76.484 & 2 & 2 \\
\hline 3 & Japão (JP) & 58.935 & 8 & 9 \\
\hline 4 & Alemanha (DE) & 28.102 & 5 & 5 \\
\hline 5 & França (FR) & 17.634 & 17 & 22 \\
\hline 6 & Reino Unido (GB) & 16.052 & 12 & 8 \\
\hline 7 & União Soviética (SU) & 8.744 & $\mathrm{~N} / \mathrm{A}$ & $\mathrm{N} / \mathrm{A}$ \\
\hline 8 & Coreia (KR) & 8.241 & 18 & 26 \\
\hline 9 & Federação Russa (RU) & 6.604 & 49 & 38 \\
\hline 10 & European Patent Office (EPO) & 3.454 & $\mathrm{~N} / \mathrm{A}$ & N/A \\
\hline 11 & Polônia (PL) & 3.244 & 59 & 39 \\
\hline 12 & Holanda (NL) & 2.378 & 6 & 4 \\
\hline 13 & $\begin{array}{l}\text { Alemanha, excluindo o território que, } \\
\text { antes de } 3 \text { de Outubro de 1990, constituía } \\
\text { a República Federal da Alemanha (DD) }\end{array}$ & 2.114 & $\mathrm{~N} / \mathrm{A}$ & $\mathrm{N} / \mathrm{A}$ \\
\hline 14 & Itália (IT) & 1.993 & 34 & 43 \\
\hline 15 & Suíça $(\mathrm{CH})$ & 1.874 & 1 & 1 \\
\hline 16 & Canadá (CA) & 1.854 & 23 & 14 \\
\hline 17 & Índia (IN) & 1.784 & 29 & 40 \\
\hline 18 & Ucrânia (UA) & 1.755 & 61 & 81 \\
\hline 19 & WIPO (WO) & 1.650 & $\mathrm{~N} / \mathrm{A}$ & $\mathrm{N} / \mathrm{A}$ \\
\hline 20 & Austrália (AU) & 1.459 & 27 & 21 \\
\hline 21 & Tchecoslováquia, até 1993 (CS) & 1.262 & $\mathrm{~N} / \mathrm{A}$ & $\mathrm{N} / \mathrm{A}$ \\
\hline 22 & Tailândia (TH) & 1.143 & 50 & 32 \\
\hline
\end{tabular}




\begin{tabular}{|c|c|c|c|c|}
\hline $\begin{array}{l}\text { Posição } \\
\text { Patentes }\end{array}$ & $\begin{array}{c}\text { País em que houve a } \mathbf{1}^{\text {a }} \text { Reivindicação } \\
\text { de Prioridade }\end{array}$ & $\begin{array}{l}\text { Quantidade de Famílias } \\
\text { De Patentes Publicadas }\end{array}$ & $\begin{array}{c}\text { PosiçÃo } \\
\text { ICG } 2017 \\
\text { INOVAÇÃo }\end{array}$ & $\begin{array}{c}\text { Posição } \\
\text { ICG } 2017 \\
\text { GERAL }\end{array}$ \\
\hline 23 & Finlândia (FI) & 1.111 & 4 & 10 \\
\hline 24 & Bélgica (BE) & 1.096 & 16 & 20 \\
\hline 25 & Suécia (SE) & 1.084 & 7 & 7 \\
\hline 26 & Romênia (RO) & 997 & 96 & 68 \\
\hline 27 & Áustria (AT) & 929 & 13 & 18 \\
\hline 28 & África do Sul (ZA) & 778 & 39 & 61 \\
\hline 29 & Taiwan (TW) & 605 & 11 & 15 \\
\hline 30 & Hungria (HU) & 533 & 62 & 60 \\
\hline
\end{tabular}

Fonte: Elaborada pelos autores deste artigo (2018), com dados gerados pelo Questel Orbit e adaptados de WEF (2018)

Neste Quadro 4 verifica-se mais uma vez a presença da China, Estados Unidos, Japão, Alemanha e França entre os principais países. A grande diferença está na saída do Brasil e da Espanha e a entrada da Hungria e de Taiwan. Ou seja, Brasil e Espanha são países em que os titulares buscam reivindicar patentes, porém não se encontram entre os países em que se busca a prioridade. De maneira geral, verifica-se que os titulares buscam reivindicar patentes prioritariamente em sua origem, e sendo assim, China, Japão e Estados Unidos tendem a apresentar um maior número de titulares de patentes no âmbito da Classificação IPC C10.

\section{Considerações Finais}

O objetivo do presente trabalho foi o de, a partir da análise de séries de dados históricas, verificar se o investimento tecnológico por meio de patentes está necessariamente ligado à competitividade de um determinado país e ao progresso técnico e à geração de receita de suas indústrias petroquímicas.

Os países que se destacam quanto ao número de prioridades de publicação de patentes reivindicadas no cenário de Indústrias de petróleo, gás ou coque; Gases técnicos contendo monóxido de carbono; Combustíveis; Lubrificantes; Turfa são aqueles que se destacam sob o aspecto de competitividade global ?

O presente trabalho buscou utilizar-se de diferentes indicadores para efetuar esta análise:

a) Produto Interno Bruto - Paridade do Poder de Compra (PIB PPC);

b)Quantidade de publicação de patentes com reivindicação de prioridade em um determinado país;

c) Índice de Competitividade Global (ICG).

Verificou-se por meio do trabalho uma forte ligação entre o número de depósitos de patentes com o PIB PPC e o nível de investimento em P\&D. Ao analisar o PIB PPC (Produto Interno Bruto - Paridade do Poder de Compra) dos 15 (quinze) principais países no ano de 
2017, verificou-se a presença dos seguintes países, respectivamente: China, Estados Unidos, Índia, Japão, Alemanha, Rússia, Brasil, Reino Unido, França, Itália e Coreia.

Ainda, conforme o Quadro 3, tendo-se em vista o Índice de Competitividade Global (ICG) estabelecido pelo Fórum Econômico Mundial, para a Edição 2017-2018, entre os 137 (cento e trinta e sete) países avaliados, para o $12^{\circ}$ Pilar, Inovação, países como os Estados Unidos; Alemanha; Reino Unido; Japão; França; Coreia; China; Rússia; Índia e Itália se destacam sob o ponto de vista de reivindicação de prioridade de patentes, mas não necessariamente estes resultados se refletem no Índice de Competividade Global.

Estes países incluem os principais consumidores de polímeros no mundo: Estados Unidos, China, Índia, Japão, Alemanha, Coreia do Sul, Itália, Brasil, Comunidade dos Estados Independentes (CEI) e França, sendo que os preços internacionais sofrem a influência de demanda dos seguintes países ou blocos econômicos: Estados Unidos, União Europeia e China.

Este fato valida o exposto pela Indian Oil (2016), quanto ao direcionamento de esforços para 3 (três) fatores principais: energia e matérias-primas; crescimento da demanda; e tecnologia.

Portanto, ainda que determinados países se destaquem quanto ao número de reivindicações de prioridades de publicação de patentes, quanto ao índice de competitividade global e quanto ao PIB PPC, esta correlação não é aplicável à totalidade dos países.

\section{Referências}

AXONAL. Treinamento Questel Orbit UNICAMP. D isponível em: < http://www.axonal.com.br/ capacitacao_info.php?id=114>. Acesso em: 27 ago. 2017.

CETINKAYA, Eren; LIU, Nathan; SIMONS, Theo Jan; WALLACH, Jeremy. Petrochemicals 2030 : Reinventing the way to win in a changing industry. 2017. Disponível em: <https:/www.mckinsey. com/industries/chemicals/our-insights/petrochemicals-2030-reinventing-the-way-to-win-in-achanging-industry >. Acesso em: 20 abr. 2018.

CONFEDERAÇÃO NACIONAL DA INDÚSTRIA (CNI). Propriedade Intelectual para o

Desenvolvimento Industrial. 2018. Disponível em: <http://www.portaldaindustria.com.br/cni/ canais/propriedade-intelectual/numeros/> . Acesso em: 20 abr. 2018.

DEPEC-BRADESCO. Química e Petroquímica. Junho de 2017. Disponível em: < https://www. economiaemdia.com.br/EconomiaEmDia/pdf/infset_quimica_e_petroquimica.pdf $>$. Acesso em: 20 abr. 2018.

FUNDAÇÃO ALEXANDRE DE GUSMÃO (FUNAG). 2017. As 15 maiores economias do mundo. Disponível em: <http:/www.funag.gov.br/ipri/index.php/o-ipri/47-estatisticas/94-as-15-maioreseconomias-do-mundo-em-pib-e-pib-ppp>. Acesso em: 26 abr. 2018.

INDIAN OIL. Petrochemicals Vision 2025: Challenges \& Opportunities. Mumbai: 5th Indian Oil Petrochemical Conclave, 2016. Disponivel em: <http://www.petrochemconclave.com/ presentation/2016/Mr.SMitra.pdf>. Acesso em 20 fev. 2018.

INSTITUTO NACIONAL DA PROPRIEDADE INDUSTRIAL (INPI). Rio de Janeiro: INPI, 2016. Busca de Patentes. Disponível: <http://www.inpi.gov.br/menu-servicos/informacao/busca-depatentes>. Acesso em: 20 abr. 2018. 
Inventando o futuro: uma introdução às patentes para as pequenas e médias empresas. Rio de Janeiro: INPI, 2013. Disponível em: < http://www.inpi.gov.br/sobre/arquivos/03 cartilhapatentes_21_01_2014_0.pdf>. Acesso em: 27 ago. 2017.

Classificação de Patentes. Disponível em: <http://www.inpi.gov.br/menu-servicos/ patente/classificacao-de-patentes>. Acesso em: 21 dez. 2017.

ORGANIZAÇÃO PARA A COOPERAÇÃO E DESENVOLVIMENTO ECONÓMICO (OECD). Glossary of Patent Terminology. 2006. Disponível em: <https://www.oecd.org/sti/scitech/37569498.pdf>. Acesso em: 20 nov. 2017.

PINHEIRO, Maurício Canêdo; FIGUEIREDO, Paulo N. Por que é tão necessário o fortalecimento da competitividade industrial do Brasil? E qual é o papel da produtividade e da capacidade tecnológica inovadora? Technological Learning and Industrial Innovation Working Paper Series, 2015. Disponível em: < https://bibliotecadigital.fgv.br/dspace/bitstream/handle/10438/19438/2015-11.2.pdf?sequence $=1 \&$ isAllowed $=y>$. Acesso em: 03 mai. 2018.

VIANA, Fernando L. E. Indústria Petroquímica. Caderno Setorial ETENE, Banco do Nordeste, 2016. Disponível em: <https://www.bnb.gov.br/documents/80223/2666752/17_petro_V2.pdf/ c99a1b65-d39a-b572-c877-5a3aeb52838c>. Acesso em: 18 abr. 2018.

WORLD ECONOMIC FORUM (WEF). The global competitiveness report 2014-2015: full data edition. Genebra, 2014. Disponivel em: <http://www3.weforum.org/docs/WEF_ GlobalCompetitivenessReport_2014-15.pdf>. Acesso em: 18 abr. 2018.

Global Competitiveness Index 2017-2018. Disponível em: <http://reports.weforum. $\overline{\mathrm{org} / \mathrm{glob}}$ al-competitiveness-index-2017-2018/countryeconomy-profiles/\# economy=BRA $>$. Acesso em: 18 abr. 2018.

\section{WORLD INTELLECTUAL PROPERTY ORGANIZATION (WIPO). Patent Cooperation Treaty} (PCT). WIPO: Washington, 1970. Disponível em: <http://www.inpi.gov.br/menu-servicos/patente/ pct.pdf > . Acesso em: 13 abr. 2018.

PCT FAQs - Protecting your Inventions Abroad: Frequently Asked Questions About the Patent Cooperation Treaty (PCT). WIPO, 2017. Disponível em: <http:/www.wipo.int/pct/en/faqs/ faqs.html>. Acesso em: 18 abr. 2018.

\section{Sobre os autores}

\section{Eduardo Cardoso Garrido}

E-mail: eduardocardosogarrido@gmail.com

Graduado em Engenharia Sanitária e Engenharia Ambiental pela Escola Politécnica da UFBA. Graduado em Engenharia de Segurança do Trabalho pela Universidade Estácio de Sá. Especialista em Gestão Ambiental com Tecnologias Limpas pela Faculdade Área 1/ DeVry Brasil. Graduando em Direito pela Faculdade de Direito da UFBA. Mestre em Propriedade Intelectual e Transferência de Tecnologia para Inovação pela UFBA. Mestrando em Gestão da Inovação e Desenvolvimento Industrial pelo Centro Universitário SENAI CIMATEC.

Endereço Profissional: SEBRAE/BA. Rua Horácio César, 64, Dois de Julho. Salvador - BA. CEP: 40.060-350. 


\section{Renelson Ribeiro Sampaio}

E-mail:renelson@fieb.org.br

Bacharelado em Física (1973) - Departamento de Física da UFMG. Pós-Graduado (1974-75) em Física-Matemática

- UnB. Mestrado (1979) em History and Social Studies of Science - University of Sussex, Inglaterra. Doutorado

(1986) na área de Economia da Inovação Tecnológica no Science Policy Research Unit - SPRU, University of

Sussex, Inglaterra. Pós-Doutorado (2010/11), realizado no Departamento de Sociologia da Universidade de Wisconsin Madison com o Professor Erik Olin Wright.

Endereço Profissional: SENAI CIMATEC. Av. Orlando Gomes, 1845 - Piatã, Salvador - BA. CEP: 41.650-010.

\section{Fernando Luiz Pellegrini Pessoa}

E-mail: fernando.pessoa@fieb.org.br

Graduado em Engenharia Química pela Universidade Federal da Bahia (1981). Especialista em Engenharia Petroquímica (CENPEQ-PETROBRAS/UFBA). Especialista em Processos de Separação pelo Equilíbrio (COFIC / UFBA). Mestre em Engenharia Química pela Universidade Federal do Rio de Janeiro (1987). Doutor em Engenharia Química pela Universidade Federal do Rio de Janeiro e Universidade de Lyngby (Dinamarca) (1992).

Endereço Profissional: SENAI CIMATEC. Av. Orlando Gomes, 1845 - Piatã, Salvador - BA. CEP: 41.650-010. 